\title{
Comparison of Bioinspired Algorithms Applied to Cancer Database
}

\author{
Autores \\ Jesús Silva, Reynaldo Villareal-González, Noel Varela, José Maco, Martín Villón, Freddy Marín- \\ González, Omar Bonerge Pineda Lezama
}

\begin{abstract}
Cancer is not just a disease; it is a set of diseases. Breast cancer is the second most common cancer worldwide after lung cancer, and it represents the most frequent cause of cancer death in women (Thurtle et al. in: PLoS Med 16(3):e1002758, 2019, 1]). If it is diagnosed at an early age, the chances of survival are greater. The objective of this research is to compare the performance of method predictions: (i) Logistic Regression, (ii) K-Nearest Neighbor, (iii) K-means, (iv) Random Forest, (v) Support Vector Machine, (vi) Linear Discriminant Analysis, (vii) Gaussian Naive Bayes, and (viii) Multilayer Perceptron within a cancer database.
\end{abstract}

Palabras clave

Big data, Machine learning, Cancer prediction 